\title{
Cooperative Learning At A Distance: An Experiment With Wikis
}

Katherine Campbell, University of North Dakota, USA

Dee Ann Ellingson, University of North Dakota, USA

\begin{abstract}
The merits of incorporating group work into learning environments are well established. Online classes and other distance learning settings, however, can make it challenging to introduce traditional group projects. Wikis use technology to facilitate group work in distance learning settings. Wikis allow individuals in different locations to asynchronously post and edit content on a website to iteratively and cooperatively work toward a solution. We describe wikis and their use in an online MBA managerial accounting class. Student feedback on their experiences using wikis as well as instructor observations were mostly positive while negative comments were primarily administrative in nature and easily addressed. In general wikis can be implemented in any business course using group assignments. When using wikis for cooperative learning, the obstacles are minimal, but the potential benefits for students may be substantial. These benefits include developing a sense of community, participating in peer-to-peer learning and using critical thinking and communication skills while still enjoying the convenience of working asynchronously in disparate locations.
\end{abstract}

Keywords: Wiki, group learning, distance education, online class

\section{INTRODUCTION}

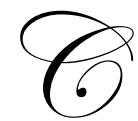

ooperative learning has long been encouraged in accounting education as a way of developing communication and teamwork skills (Cottell and Millis, 1993; Peek et al., 1995; Ravenscroft et al., 1995), which are essential in practice (Russell et al., 1999). According to Ravenscroft (1997, p. 188), "cooperative learning should take place primarily within the classroom." In recent years, however, the explosion of online courses and other distance learning venues has changed the definition of "classroom" and introduced significant challenges for incorporating group work in virtual environments. How can students in different locations, even different time zones, work collaboratively to produce a single work product? Technology, which created this dilemma, may also hold the solution. A wiki is a software tool that allows individuals to not only add content, but also edit and delete their own or another's content from a commonly accessible set of hyperlinked web pages (Mindel and Verma, 2006). This allows users to incrementally and progressively work toward a collaborative solution, even from different locations at different times (Wagner, 2004). Wikipedia, "the free encyclopedia that anyone can edit" (www.wikipedia.org), is possibly the best known wiki. But, wikis also have many applications in business, including project management (Bean and Hott, 2005), professional training (Frauenheim, 2007; Yeh, 2008), and community building (Twentyman, 2008). In academic settings wikis have been used in a variety of contexts including engineering (Ras, et. al., 2007) and business (Workman Jr., 2008; Bisoux, 2008). Wiki technology is readily available since a wiki software tool is often incorporated in learning management software such as Blackboard. Thus, wikis are a tool that can be used to facilitate group work in many distance learning environments.

The next section describes wikis along with their potential benefits as a platform for collaboration and group work. Experiences related to introducing wikis into an online MBA managerial accounting course are described in Section 3. Section 4 describes initial impressions of students and the instructor about what worked well with the wikis and where there may be opportunities for improvement. Finally, discussion and a summary are provided in Section 5. 


\section{WHY WIKIS?}

The idea for using wikis came about when preparing to teach an MBA managerial accounting course to distance learners for the first time. The class was scheduled to meet once a week for three hours in an online, Webassisted format using Adobe Connect web conferencing software. Each class participant would be at a computer with a camera and headphone. In the separate on-campus section of the course, students would participate in small discussion groups during class. One concern with the online format was finding a similar way for distance students to interact and learn from each other. A workshop on Teaching with Technology introduced a broad range of learning technologies, including threaded discussions, blogs, and wikis. While threaded discussions and blogs would allow students to discuss a question or issue, each student's contributions are discrete and do not lead to a final group outcome. Wikis were appealing because they would allow students to contribute, edit, and delete material on a common web page and to work collaboratively toward a solution. In this sense wikis were more analogous to in-class group assignments.

Wikis offer a number of potential benefits that make them attractive for distance learning environments. The interactive nature of the wikis may foster a sense community among distance students who may rarely, if ever, meet in person. This is likely to encourage participation and improve motivation among students. Wikis promote peer-to-peer learning by providing a common site for students to correct and augment each other's work as well as to provide comments and encouragement to other group members. Communication and critical thinking skills may be developed or improved through the use of wikis (Workman, 2008). Students must use written communication in the process of adding and editing wiki content and when discussing an issue or defending a position with other group members. Critical thinking is a central aspect of the process of critically analyzing another's work when editing or supplementing it on the wiki. Since distance students are probably comfortable with technology in general, the introduction of wiki technology is likely pose only a minor hurdle for these students (Ajjan and Hartshorne, 2008). A critical benefit for distance students is that wikis offer convenience by allowing students to work asynchronously from different locations. Finally, wiki software provides a history which documents each change to a wiki (Wagner, 2004). This feature allows the professor to view what changes were made, by whom, and when. With traditional group projects, the professor sees only the final output and must rely on peer evaluations to determine member contributions. When wikis are used, the wiki history allows the professor to better observe the group process and assess individual members' contributions and participation. Consideration of this set of attractive features led to an experiment with using wikis in the online MBA managerial accounting course.

\section{INTRODUCING WIKIS IN AN MBA MANAGERIAL ACCOUNTING CLASS}

\section{Class Procedures for Wikis}

The following procedures were used for the wikis. The 18 students in the class were randomly assigned to groups of three and a wiki was set up on Blackboard for each group. Each group used their wiki to prepare a solution to one of the assigned homework problems or mini-cases each week. The homework assignments consisted of computational and discussion questions on managerial accounting topics such as cost-volume-profit, incremental costs for decision-making, transfer pricing, budgeting, cost allocation, etc. For example, one assignment required students to analyze whether to discontinue a segment of a business, to compute the incremental revenues and costs associated with the decision, and discuss qualitative factors that should be considered. Assignments typically had multiple requirements to ensure that all group members could contribute.

Each group selected one person to present their group's wiki solution during class. Presentation duties were rotated until each group member had a turn. After all group members had presented a solution, the students were randomly reassigned to new groups and new wikis were created. Reassigning the students to new groups allowed them to interact with more students in the class. There were three rounds of three wiki assignments, totaling nine for the semester.

Students were graded on their participation in the wiki assignments and their presentation. To grade the wikis for participation points, the wiki history was viewed to see what was contributed, when and by whom. Groups quickly realized that they could start a new page in their wiki for each new assignment, which both helped and 
hindered the grading process. As long as each assignment was on one wiki page, viewing the history and grading participation was relatively straightforward. The history shows activity for only one page at a time, so if more than one page was used, or particularly if an entire page had been deleted, it was more challenging to find all contributions made by group members. However, deleted wiki pages could be found on the Page List link under the Toolbox rather than the history link.

The next section describes experiences using the wikis, initial impressions on how well the wikis worked, potential improvements to the way they were implemented in this course, and some student feedback.

\section{Using the Wikis}

The first wiki assignment was a learning experience for all. While it seemed that most students had a basic understanding of what a wiki was and how it worked, it appeared that no one in the class (including the professor) had prior experience working with wikis on Blackboard. Some of the students caught on right away, while others seemed to have trouble even finding it. By virtue of being in an online class, one might expect students to be more comfortable with technology, and that seemed to be the case. By the second assignment, students were much more adept at the process of developing a solution on their wiki. Each week, one student in the group would begin by opening a page in the wiki for the assignment and posting an initial solution to part of the problem. There was also a comment area on the wiki page where students could discuss or make comments to each other that would not be part of the solution they were developing. Wikis were reviewed by the professor before each class, and groups were provided feedback as needed, either via email or the comment box on the wiki. Group members would also email the professor with questions.

Presentation of wiki solutions via Adobe Connect was a bit of a challenge. When class met, each student was at a computer with a microphone and camera, so all class participants were visible to each other through the web-conferencing software. Audio was limited by bandwidth, however, so that only one microphone could be in use at a time. As more bandwidth becomes available, either through a smaller class size or improved technology, it may be possible to have a discussion among two or more people. During the wiki presentations, only the student presenter would turn on their microphone. The group's wiki solution was pulled up on the professor's computer and shared with the class while it was presented. (The students suggested that the professor give them control over their wiki during the presentation. While this is possible, the campus technology resource advisor did not recommend implementing this approach, and the professor retained control of the material visually projected to participants in this class.) The audio limitation made it difficult for students to verbally ask questions during presentations. There was, however, a chat box where students felt very comfortable sending questions or comments, very much like textmessaging. Chat entries could be sent to all participants or privately to the professor or another selected individual participant. From the professor's standpoint, it could be somewhat disconcerting and distracting to have items appear in the chat box while lecturing, but it was also nice to be able to address questions or comments at an appropriate place in the class. Students seemed much more willing to ask questions than in the on-campus section. The ability to send a question privately to the professor may explain this difference. Students may have been less intimidated to ask the professor a question privately through the chat box than to ask a question in front of all the members of the class.

\section{OBSERVATIONS AND FEEDBACK}

\section{Feedback from Students}

Students were asked to provide feedback on the course in the form of written comments to three questions: (1) Identify and discuss two things you believe were of particular value or benefit to you in the course. (2) Identify and discuss two constructive comments that you believe would benefit or improve the course. (3) Since this is my first time teaching a distance course, please give some feedback on the distance nature of the course - what seemed to work well, what could have been done differently?

Since students were not asked specifically about the wikis, it was interesting to note the number and types of comments that were made about them. Thirteen of the 18 students made some type of comment about the wikis. 
Of the comments received, thirteen were positive while eight were negative or constructive comments. (Note that some students made both positive and negative or constructive comments while a couple students made more than one positive comment.)

Positive comments dealt with student involvement and motivation, getting to know fellow students, sharing insights and learning from each other, and applying wikis to a work situation. Representative examples of positive comments include:

- $\quad$ "I felt like the wikis were beneficial in this course. Since it is a distance class, the ability to gain insight and build upon ideas from other students was very valuable."

- $\quad$ "I did like the use of Wikis and having to switch groups. It let you see how others work and their way of calculating the problem."

- $\quad$ "I thought that it was a great way for the group members to correspond to each other in an easy way, and a great way to share work."

- $\quad$ "I very much enjoyed being in the Wiki groups. It actually helped me get to know some of the other students in the class even though I am geographically distant from them."

- $\quad$ "I like the group work as it was nice to get the other group members input when working on the problems. It was also a good way to interact and meet some of the others in the class since you don't have the daily face to face contact like in a typical classroom."

- "I enjoyed the participation of the groups each week in the wiki. It provides an opportunity for involvement, accountability, and points toward our grade."

- $\quad$ "Wikis were new to me. I greatly enjoyed having a common place to check and work on a group project. I work at an extended site from our main office so the use of wikis will be very helpful when we need to collaborate on a project."

Negative or constructive comments could be grouped into three categories; preference for keeping the same group for the semester rather than switching three times, frustration with a group member for posting complete solutions and feeling like they weren't able to contribute, and dislike for the asynchronous nature of the wiki and the timing of posts and responses. Representative examples of comments include:

- $\quad$ "Stick with one group over the course of the semester, so that you actually have the opportunity to network with those students and benefit from a more advanced group formation stage."

- $\quad$ "By the time I have a chance to begin working on the assignment, someone in the group had finished the entire problem. Then I felt stuck because at that point there really wasn't a way for me to contribute."

- $\quad$ "It was tough to coordinate the assignments with two others and it seemed that each person tended to do the assignments on there (sic) own and post his or her worksheet. In all three groups I was involved with, we never experienced anybody working on or improving on another's work."

- $\quad$ "Often if I put something on the wiki, it would take too long for my group... to reply. With my schedule, I usually only had one night a week to commit to my homework."

Some of these comments might have been related to the particular groups to which the students were assigned, as some groups worked more effectively than others. But, most of these comments could be addressed by changes in the way assignments were structured and/or the wikis were implemented. Interestingly, students in the on-campus section became aware that wikis were being used in the distance class and recommended that wikis be used for the on-campus class, too. The on-campus students thought the wikis sounded like a great way to motivate them to do homework and keep up with course material.

\section{Professor's Observations}

Throughout the semester, observations were made on how groups were using the wikis, especially when reviewing the wiki histories. The primary objective in introducing wikis was to provide a means for student interaction and peer-to-peer learning in the online course. Both student feedback and the professor's observations suggest that the wikis met this objective. Wikis also appear to have enhanced students' engagement in the course 
and encouraged students to interact with and learn from each other. This was observable in several ways. There were very few times when an individual student failed to participate in the week's wiki assignment. While points were awarded for participation in wiki assignments, the points for each assignment were a minor part of the course grade (less than one percent) and alone would not be sufficient to motivate the students. Student presentations of the wikis were particularly helpful in facilitating peer-to-peer learning as students sometimes used a different approach or thought process than the professor or the textbook. While a few student comments suggested that different approaches were confusing, more often students appreciated a peer's approach and sometimes found it made more sense to them. Different perspectives were particularly beneficial when students shared an experience or application from their work that was related to the topic. Students shared these insights via wikis, presentations and the chat box. One caveat is that this was the first online-interactive course taught by this professor, and thus no comparison could be made with a comparable online course without wikis. There was, however, also a concurrent on-campus section of this course. The on-campus students were assigned to in-class discussion groups instead of wikis and had several graded homework assignments in place of wiki participation points. Attendance by the online students was far better than the on-campus students, and almost without fail, online students gave notice if they had to miss class. While many factors might explain the difference in motivation level between the online and on-campus students, the wikis may have played a role.

Another observation was that wikis worked better for open-ended mini-cases or questions than for numerical problems with a definitive "right" answer. For narrative responses to open-ended questions, the students were more likely to write directly to the wiki than to upload a document. This approach facilitated group members' ability to add to or edit comments, although it appeared that students were a bit reluctant to delete or significantly modify another student's contributions. Students would more typically add to or clarify previous posts. The openended questions also allowed for more input from group members, as each could provide their own perspective and could make some type of contribution. For numerical problems, however, students often uploaded an Excel file, which was difficult for other students to access and modify. As one student pointed out, he could access and modify another student's spreadsheet file but couldn't save it to the wiki. As a result, each student posted their own spreadsheet file, presumably to prove they had done the problem and should receive the participation points. This circumvented one purpose of the wiki, to work as a group to modify and improve their solution. It also complicated grading the wikis since this required opening all the spreadsheet files and trying to identify what, if anything, was modified or contributed in subsequent posts.

It was interesting to observe the group process and the timing of the posts on the wikis. As one might expect, procrastinators posted shortly before class, which did not allow time for others to edit or add to their posts. In a very few cases, there were also those who did not post to the wiki at all. The opposite problem also arose. There were those who posted complete, correct solutions early, leaving nothing for other group members to contribute. This was a source of frustration for fellow group members, as some of the comments in the student feedback illustrate.

\section{CONCLUSIONS}

Feedback from the students regarding the wikis was largely positive. Positive student comments outweighed negative comments not only in number but also in substance. Many of the positive comments were consistent with the benefits of wikis described in the literature. Most of the negative comments were more administrative in nature and could be addressed with additional instruction on the use of the wikis, guidance as to postings, and structure of assignments. In the future, most concerns could be addressed by implementing the following guidelines for wiki use: 1. a new "page" in the wiki should be created for each assignment; 2.each member should post only a part of the solution to the wiki to allow other group members to contribute. Additional postings may be made when either (a) it is within 24 hours of the next class meeting, or (b) all group members have contributed. 3. Content should be copied and pasted to the wiki rather than uploaded in a Word or Excel document since an uploaded document cannot be edited by other group members.

The observations and student feedback discussed above provide anecdotal evidence that is consistent with many of the assertions found in the literature regarding wikis. The observations and student feedback suggest that wikis promoted student interaction and peer-to-peer learning (Wagner, 2004), which was the primary objective in 
introducing the wikis in the distance class. The wikis appeared to be more effective when used for open-ended questions and mini-cases (Wagner, 2004) than definitive numerical problems. The students' familiarity with technology (Ajjan and Hartshorne, 2008) likely contributed to their quick adaptation to using wikis. At least one student stated that they anticipated using wikis in their work setting (Twentyman, 2008). The development of communication and critical thinking skills (Workman, 2008) was not specifically observed here, although one might surmise that developing such skills was an implicit part of completing wiki assignments. Analyzing the development of communication and critical thinking skills may be an avenue for future research given the ability to observe the history of the wiki posts and to longitudinally study the evolution of skills applied by groups in wiki solutions developed over the course of the semester. The wiki history also documents the group process, and this was one of the most beneficial aspects of wikis from the professor's viewpoint. This was particularly helpful for grading participation, as each group member's contributions could be assessed. Such observation would also be useful for understanding the group process and facilitating the development of teamwork skills desired by employers. Since this was the first experience using wikis, the professor made no attempts to observe or direct group processes or enhance the development of teamwork skills. Future research may include further investigation into the group processes observed in the wikis and opportunities to assist students in developing teamwork skills.

While we describe the way wikis were introduced into an online graduate managerial accounting course, wikis could be implemented in any accounting or business course using cooperative learning or group exercises. The primary obstacles to implementing wikis are availability of software, familiarizing students and instructors with wikis, and developing guidelines for implementing wikis in different class settings. In general, these obstacles are minimal. While introducing wikis requires some up-front investment of time on the part of instructors, in comparison to the potential benefits the overall cost is quite low. The benefits for distance students can be substantial. These benefits include developing a sense of community, participating in peer-to-peer learning and developing communication and critical thinking skills. One of the most substantial benefits for students, however, is convenience. Wikis allowed students to enjoy the benefits of collaboration while working asynchronously in disparate locations. While this feature was critical for distance students, for whom there are few practical alternatives for integrating truly cooperative work without imposing significant coordination costs, this is also a potentially appealing feature for students enrolled in traditional classroom-based courses. For instructors, wikis offer the unique feature of providing a window onto group process through the wiki history. Compared to traditional group work, this wiki feature offers instructors new avenues for monitoring, assessing, and improving students' group process. Overall, the benefits of using wikis are likely to enhance most students' level of engagement and overall learning experience.

\section{REFERENCES}

1. Ajjan, Haya and Richard Hartshorne (2008). Investigating faculty decisions to adopt Web 2.0 technologies: Theory and empirical tests. Internet and Higher Education, 11, 71-80.

2. Bean, LuAnn and David D. Hott (2005). Wiki: A speedy new tool to manage projects. Journal of Corporate Accounting \& Finance, 16(5), 3-8.

3. Bisoux, Tricia (2008). Teaching business in a Web 2.0 world. BizEd, January/February, 28-35.

4. Cottell, Philip G. Jr., and Barbara J. Millis. (1993). "Cooperative Learning Structures in the Instruction of Accounting." Issues in Accounting Education, Spring, 40-59.

5. Frauenheim, Ed (2007). Your co-worker, your teacher: Collaborative technology speeds peer-peer learning. Workforce Management, 86(2), 19-23.

6. Mindel, Joshua L. and Sameer Verma (2006). Wikis for teaching and learning. Communications of AIS, $18,265-289$.

7. Peek, Lucia E., Charles Winking, and George S. Peek. (1995). "Cooperative Learning Activities: Managerial Accounting." Issues in Accounting Education, Spring, 111-125.

8. Ras, Eric, Ralf Carbon, Bjorn Decker, and Jorg Rech (2007). Experience management wikis for reflective practice in software capstone projects. IEEE Transactions on Education, 50(4), 312-320.

9. Ravenscroft, Susan P., Frank A. Buckless, Gary B. McCombs, and Gilroy J. Zuckerman. (1995). "Incentives in Student Team Learning: An Experiment in Cooperative Group Learning." Issues in Accounting Education, Spring, 97-109. 
10. Ravenscroft, Susan P. (1997). "In Support of Cooperative Learning." Issues in Accounting Education, Spring, 187-198.

11. Russell, Keith A., Gary H. Seigel, and C. C. Kulesza. (1999). Counting More, Counting Less. Strategic Finance, September, 81 (3), 38-44.

12. Twentyman, Jessica (2008). Wiki while you work. Personnel Today, April 29, 26-27.

13. Wagner, Christian (2004). Wiki: A technology for conversational knowledge management and group collaboration. Communications of the Association for Information Systems, 13, 265-289.

14. Workman, Jr., John P. (2008). Wikis in the classroom: Opportunities and challenges. Marketing Education Review, 18(1), 19-24.

15. Yeh, Chris (2008). Wiki training increases productivity for RMC Vanguard Mortgage. Chief Learning Officer, July, 37. 
NOTES 